\title{
The role of need for achievement in self-leadership: Differential associations with hope for success and fear of failure
}

\author{
Marco R. Furtner* and John F. Rauthmann \\ Leopold-Franzens University of Innsbruck, Austria. \\ Accepted 25 May, 2011
}

\begin{abstract}
Self-leadership and need for achievement show conceptual convergences as both constructs have been found to be phenotypically associated with heightened levels of performance (Neck and Manz, 1992; Spangler, 1992). We thus aimed to clarify how both are interrelated with their respective subfacets in three studies $(N=185, N=228, N=374)$ and found that (a) self-leadership and need for achievement tap different domains, (b) self-leadership is differentially associated with hope for success versus fear of failure, and (c) concurrent live contexts may play a role in associations. Specifically, most selfleadership facets are related to hope for success, but self-punishment and natural reward strategies are positively and negatively related to fear of failure, respectively. Limitations and future research possibilities are discussed.
\end{abstract}

Key words: Self-leadership, need for achievement, achievement motivation, hope for success, fear of failure.

\section{INTRODUCTION}

Two constructs are associated with positive work-related outcomes: self-leadership and need for achievement (nAch). While need for achievement (nAch) has been extensively studied (Spangler, 1992), the empirical basis for self-leadership is rather sparse (Furtner et al., 2011; Manz, 1986; Markham and Markham, 1995; Neck and Houghton, 2006). Both constructs show phenotypical similarities such as intrinsically motivated working, enjoyment of tasks, and heightened performance, yet they are on different conceptual levels. Self-leadership subsumes cognitive and behavioral self-regulatory strategies, and nAch taps dispositional motives. According to Neck and Houghton (2006), a crucial problem of self-leadership is that it may not be distinct from classical motivational constructs. In this work, we provide clarification of how self-leadership, with its subfacets, is linked to nAch, with hope for success and

${ }^{\star}$ Corresponding author. E-mail: Marco.Furtner@uibk.ac.at. Tel: +435125075555. fear of failure, in student and professional samples.

\section{THEORETICAL BACKGROUND}

\section{Self-leadership}

Self-leadership, an extension of self-management emphasizing behavior-focused strategies, comprises regulatory components and intrinsic motivation (Manz, 1986). Houghton and Neck (2002) distinguished three primary strategy dimensions: behavior-focused strategies (selfgoal setting, self-reward, self-punishment, self-observation, self-cueing), natural reward strategies (intrinsic motivation), and constructive thought patterns (visualizing successful performance, self-talk, evaluating beliefs and assumptions). With behavior-focused strategies, attention to one's behaviors and focus on discrepancies between perceived current, prospective, and desired states can be enhanced. Discrepancies are then diminished by selfregulatory strategies (Carver and Scheier, 1998). Put in a performance context, an individual must first set goals 
and then monitor own actions in the process of goalpursuit in order to achieve higher performance. Natural reward strategies are related to intrinsic motivation (Deci and Ryan, 1985), and tasks are or becoming intrinsically motivating to an individual (Neck and Houghton, 2006). Intrinsic motivation originates once an individual is immerged into a task - independent of any extrinsic inducements - so that the task itself is experienced as positive and associated working processes as rewarding. This process gives rise to feelings of competence and self-determination (Deci and Ryan, 1985), which links self-leadership to motivational constructs. Constructive thought patterns encompass the (positive) influence and control of habitual thinking patterns which consequently influence individual levels of performance (Neck and Manz, 1992). It is important to keep oneself motivated in the process of goal pursuit by visualizing (successful) performance as well as evaluating own thoughts and behaviors. This should lead to sustaining motivation and thus also to enhanced performance.

\section{Need for achievement}

Murray (1938) first described a need for achievement, (nAch), in his list of 20 needs, and it has been treated besides the need for affiliation and need for power as a central human motive (McClelland, 1965; McClelland et al., 1989). People scoring high on nAch are motivated to show high performance and fulfill high internal standards and goals (Robbins et al., 2004; Spangler, 1992). According to Atkinson's (1957), risk preference model of choice- and risk-taking behavior, nAch consists of two central components, an approach and an avoidance tendency (Elliot and Church, 1997). The former is associated with hope for success, the latter with fear of failure (Elliot, 2006; Lang and Fries, 2006) which are both forms of nAch and bring forth achievement-related behavior. Explicit nAch captures cognitively represented self-concepts and goals (McClelland et al., 1989). Regulatory strategies - such as self-leadership - may thus be linked primarily to explicit motives as these can be cognitively modulated.

\section{Self-leadership and the need for achievement}

Self-leadership has been conceptualized as a dimension subsuming different self-regulatory strategies, and most of these are grounded in theories of human motivation (Neck and Houghton, 2006). NAch can be seen as an individual predisposition to self-management and selfleadership (Manz, and Sims, 1980). Self-leadership (for example, self-goal setting, visualizing successful performance) and nAch conceptually focus on processes of goal setting and pursuit (Elliot, 2006). Elliot and Fryer (2008) defined goals as cognitive representations of future objectives that are either approached or avoided. Goals may then provide the motivational basis for selfregulation as goals focus on a specific final state that should be achieved. According to McClelland et al. (1989), explicit nAch leads to conscious and volitional intent or goal setting. Motivation for goal achievement arises from a dispositional motive (Elliot and Church, 1997), and thus nAch could affect the use of self-leading strategies (for example, goal setting) positively. Lang and Fries (2006) showed strong positive relationships for hope for success with task-related goal-setting, positive self-evaluation, and task-related intrinsic motivation, and negative relationships for fear of failure with self-evaluation and task-related goal-setting. Thus, the evidence in the literature already indirectly links nAch to selfleadership, and hope for success should be positively and fear of failure negatively associated with self-leadership strategies. Furthermore, nAch and self-leadership share (a) conceptual similarities (focus on goal pursuit), (b) similar phenotypical processes, and (c) similar real-life outcomes (for example, heightened performance), which suggests that these constructs stand in close association.

\section{The present studies}

We empirically investigate associations among self-leadership (with subfacets) and nAch (with hope for success and fear of failure) in three studies. Although self-leadership and $n A c h$ are on different conceptual levels and certainly distinct constructs, it has been lamented that self-leadership is not well distinguished from traditional motivation theories (Guzzo, 1998; Markham and Markham, 1995; Neck and Houghton, 2006). Clarification on the relationships between self-leadership and nAch are thus needed to gain a more differentiated picture.

We formulated two hypotheses based on the literature. First, we hypothesized that self-leadership and subfacets are positively related to nAch as a global factor, and investigate this in Study 1. Secondly, we hypothesized that self-leadership and sufacets would be more strongly related to hope for success rather than fear of failure (cf. Lang and Fries, 2006; Neck and Houghton, 2006), which we investigated in Studies 2 and 3 in different samples (students vs. professionals). We employed different samples because life contexts and normative pressures (university vs. work) may alter associations as goals as well as their pursuit are likely to differ for different age groups as a function of their differential environments and social roles (being a student vs. being a worker).

\section{EXPERIMENTAL PROCEDURE}

\section{Studies 1, 2 and 3}

In Study 1 , we investigated $\mathrm{H}_{1}$ in a student sample to see whether and how self-leadership (and subfacets) is associated with global nAch.

Study 1 had only a global nAch measure. In Study 2, we used the most widely used explicit achievement motive scale with subscales hope for success and fear of failure to gain a more differentiated view on self-leadership - nAch associations and investigate $\mathrm{H}_{2}$. 
Studies 1 and 2 were limited to student samples and thus to contexts of university and student life. In Study 3 , we used the same measures and procedures in a professionally experienced sample (with a balanced male:female ratio) to account for possible sample, age, and context specificity in self-leadership - nAch associations.

\section{Methods}

\section{Participants and procedure}

In Study 1, 185 fresh male and female students (135 women, 49 men; one person did not indicate sex; $M=22.47$ years, $S D=2.68$, range: 19 to 34 ) provided paper and pencil self-ratings on selfleadership and nAch. All students obtained credit points in exchange for participating.

In Study 2, 285 male and female students (169 women, 59 men; $M=22.54$ years, $S D=5.30$, range: 18 to 63 ) provided paper and pencil self-ratings on self-leadership and nAch. All students obtained credit points in exchange for participating.

In Study 3, 374 professionals (182 women, 192 men; $M=40.91$ years, $S D=11.91$, range $19-66$ ) provided paper and pencil selfratings on self-leadership and nAch. $90.9 \%$ of participants had leadership experience and $100 \%$ working experience for at least more than a year. Professions were sampled from different branches and organizations to obtain more variety than was the case in Studies 1 and 2 (that is, it is likely that people had to deal with different goals and strategies for pursuit and self-regulation).

\section{Measures}

Study 1: Self-leadership was measured with a German version of Houghton and Neck's (2002) original self-leadership scale (RSLQD; Andressen and Konradt, 2007), containing 27 items to be answered on a five-point Likert scale (from 1 'totally disagree' to 5 'totally agree'). Example items are "I establish specific goals for my own performance" and "I usually am aware of how well I'm doing as I perform an activity".

NAch was measured with a German short version (30 items) of the Achievement Motivation Inventory on a seven-point Likert scale (from 1 'totally disagree' to 7 'totally agree') from Schuler and Prochaska (2001). Example items are "I am especially intrigued by tasks which I am not sure I can solve" and "I love to seek tasks that challenge my skills".

Study 2: The same self-leadership scale as in Study 1 was used. NAch was measured with a revised German version of the Achievement Motives Scale (AMS-R; Lang and Fries, 2006), containing 10 items to be answered on a four-point Likert scale (from 1 'totally disagree' to 4 'totally agree'). Example items are "I'm excited by situations in which I can test my skills" (hope for success) and "I fear tasks that l'm not able to complete - even if no one recognized my failure" (fear of failure).

Study 3: The same measures as in Study 2 were used.

\section{Statistical analyses}

Study 1: Bivariate zero-order Pearson correlation coefficients were computed to obtain a general picture of linear interrelationships between variables.

Study 2: First, bivariate zero-order Pearson correlation coefficients were computed to obtain a general picture of linear interrelationships between variables. Second, joint exploratory factor analyses with different extraction (principal components vs. principal axis factoring) and rotation methods (direct-oblimin with $\delta$ $=0$ and promax with $\mathrm{K}=4$ ) were computed to assess dimensional structural relations between variables. As results from factor analyses converged, we only report principal axis factoring with promax-rotation.

Study 3: The same data-analytical procedures as in Study 2 were used.

\section{RESULTS}

\section{Study 1}

Correlations, means, standard deviations, and internal consistencies (Cronbach's alpha) for all scales in all three studies can be found in Table 1. As can be seen under Study 1 in Table 1, nAch was positively correlated with all nine Self-leadership subfacets $(r s=0.18$ to $0.59 ; p<$ $0.05)$ and global Self-leadership $(r=0.60, p<0.001)$. Correlations were thus all in a moderate range. Correcting for attenuation due to scale unreliability, the correlation between natural reward strategies and global nAch rose from $r=0.41$ to $0.70(p<0.001)$.

\section{Study 2}

As can be seen under Study 2 in Table 1, almost all selfleadership scales (except self-reward, natural reward strategies, and evaluating beliefs and assumptions; $p$ s > 0.05 ) were significantly positively correlated with global nAch ( $r s=0.14$ to 0.37 , ps $<0.05$ ) although correlations were generally lower than in Study 1. Global selfleadership correlated significantly positively with hope for success $(r=0.27, p<0.001)$, but not with fear of failure $(r$ $=0.05, p>0.10)$. Differential associations for each of the three strategy domains were found: Behavior-focused strategies were positively related to both hope for success and fear of failure, natural reward strategies positively to hope for success (disattenuated: $r=0.33, p$ $<0.01$ ) and negatively to fear of failure (disattenuated: $r=$ $0.38, p<0.01$ ), and constructive thought patterns only to hope for success. Only self-punishment and self-talk correlated positively with fear of failure. Overall, correlational results suggest that self-leadership is positively associated with nAch as most self-leadership subfacets are positively related to hope for success. The correlation between natural reward strategies and global nAch was canceled out due to a positive correlation with hope for success and a negative one with fear of failure.

Additionally, we conducted a joint exploratory factor analysis (principal axis factoring, promax-rotation with $\mathrm{K}=$ 4) of self-leadership facet scales and nAch (hope for success and fear of failure). Velicer's Map test, Horn's parallel analysis, and the scree-plot inspection suggested extraction of only two variables (despite an initial fourfactor solution), accounting for $30.88 \%$ of total variance 
Table 1. Descriptive statistics and bivariate correlations among self-leadership and need for achievement in Studies 1,2 , and 3.

\begin{tabular}{|c|c|c|c|c|c|c|c|c|c|c|c|c|c|c|c|c|}
\hline \multirow[b]{2}{*}{ Scales } & \multicolumn{4}{|c|}{ Study 1} & \multicolumn{6}{|c|}{ Study 2} & \multicolumn{6}{|c|}{ Study 3} \\
\hline & $M$ & $S D$ & $\alpha$ & $\begin{array}{l}\text { LMI-K } \\
\text { nAch }\end{array}$ & $M$ & $S D$ & $a$ & $\begin{array}{l}\text { AMS } \\
\text { nAch }\end{array}$ & $\begin{array}{c}\text { AMS } \\
\text { hope for } \\
\text { success }\end{array}$ & $\begin{array}{c}\text { AMS } \\
\text { fear of } \\
\text { failure } \\
\end{array}$ & $M$ & $S D$ & $\alpha$ & $\begin{array}{l}\text { AMS } \\
\text { n-ach }\end{array}$ & $\begin{array}{c}\text { AMS } \\
\text { hope for } \\
\text { success }\end{array}$ & $\begin{array}{l}\text { AMS } \\
\text { fear of } \\
\text { failure }\end{array}$ \\
\hline \multicolumn{17}{|l|}{ Need for achievement } \\
\hline Global need for achievement & 4.61 & 0.85 & 0.94 & - & 2.91 & 0.34 & 0.61 & - & & & 2.77 & 0.38 & 0.66 & - & & \\
\hline Hope for success & - & - & - & - & 3.26 & 0.47 & 0.79 & - & - & & 3.34 & 0.49 & 0.81 & - & - & \\
\hline Fear of failure & - & - & - & - & 2.56 & 0.61 & 0.82 & - & $-0.23^{\star *}$ & - & 2.20 & 0.68 & 0.86 & - & $-0.21^{\star * *}$ & - \\
\hline \multicolumn{17}{|l|}{ Self-leadership } \\
\hline Global self-leadership & 3.66 & 0.53 & 0.83 & $0.60^{* * *}$ & 3.72 & 0.39 & 0.85 & $0.23^{* *}$ & $0.27^{* * *}$ & 0.05 & 3.49 & 0.53 & 0.91 & $0.33^{* * *}$ & $0.41^{* * *}$ & 0.06 \\
\hline Behavior-focused strategies & 3.72 & 0.59 & 0.84 & $0.53^{* * *}$ & 3.68 & 0.48 & 0.74 & $0.35^{* * *}$ & $0.24^{* * *}$ & $0.21^{* *}$ & 3.36 & 0.64 & 0.88 & $0.36^{* * *}$ & $0.33^{* * *}$ & $0.15^{* *}$ \\
\hline Self-goal setting & 3.75 & 0.84 & 0.78 & $0.59^{* * *}$ & 3.85 & 0.62 & 0.65 & $0.29^{* * *}$ & $0.33^{\star * *}$ & 0.07 & 3.52 & 0.74 & 0.68 & $0.22^{\star * *}$ & $0.35^{* * *}$ & -0.01 \\
\hline Self-reward & 4.00 & 0.98 & 0.93 & $0.18^{*}$ & 3.70 & 1.00 & 0.95 & -0.02 & 0.01 & -0.02 & 2.95 & 1.12 & 0.93 & $0.21^{* * *}$ & $0.14^{* *}$ & $0.13^{*}$ \\
\hline Self-punishment & 3.69 & 0.96 & 0.85 & $0.21^{* *}$ & 3.70 & 0.86 & 0.85 & $0.37^{* * *}$ & 0.02 & $0.40^{* * *}$ & 3.45 & 0.84 & 0.79 & $0.39^{* * *}$ & $0.21^{* * *}$ & $0.28^{* * *}$ \\
\hline Self-observation & 3.76 & 0.71 & 0.73 & $0.52^{* * *}$ & 3.74 & 0.68 & 0.77 & $0.31^{* * *}$ & $0.36^{* * *}$ & 0.07 & 3.62 & 0.78 & 0.77 & $0.33^{* * *}$ & $0.44^{* * *}$ & 0.05 \\
\hline Constructive thought patterns & 3.46 & 0.67 & 0.83 & $0.52^{* * *}$ & 3.52 & 0.57 & 0.81 & $0.24^{* * *}$ & $0.19^{* *}$ & $0.12 \dagger$ & 3.37 & 0.67 & 0.83 & $0.27^{* * *}$ & $0.34^{* * *}$ & 0.05 \\
\hline $\begin{array}{l}\text { Visualizing successful } \\
\text { performance }\end{array}$ & 3.19 & 0.92 & 0.74 & $0.46^{* * *}$ & 3.35 & 0.81 & 0.79 & $0.19^{\star *}$ & $0.16^{*}$ & 0.09 & 3.25 & 0.92 & 0.72 & $0.19^{\star * *}$ & $0.25^{\star * *}$ & 0.02 \\
\hline Self-talk & 3.47 & 0.87 & 0.77 & $0.39^{* * *}$ & 3.51 & 0.76 & 0.74 & $0.23^{* * *}$ & $0.14^{*}$ & $0.15^{*}$ & 3.41 & 0.82 & 0.74 & $0.30^{* * *}$ & $0.32^{* * *}$ & $0.10 \dagger$ \\
\hline $\begin{array}{l}\text { Evaluating beliefs and } \\
\text { assumptions }\end{array}$ & 3.71 & 0.74 & 0.76 & $0.36^{* * *}$ & 3.70 & 0.66 & 0.72 & $0.12 \dagger$ & $0.14^{*}$ & 0.02 & 3.43 & 0.73 & 0.75 & $0.17^{* *}$ & $0.26^{* * *}$ & 0.00 \\
\hline
\end{tabular}

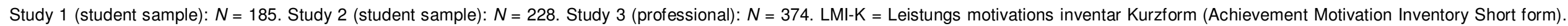
AMS $=$ Achievement Motive Scale. $\mathrm{nAch}=$ need for achievement. ${ }^{* * *} p<0.001,{ }^{* *} p<0.01,{ }^{*} p<0.05, \dagger p<0.10$.

(factor 1: $21.68 \%$, factor 2: $9.2 \%$ ). Factor 1 consisted of hope for success and self-leadership facets, and Factor 2 of fear of failure and selfpunishment. The factor diagram can be seen in Figure $1 \mathrm{~A}$.

\section{Study 3}

As can be seen under Study 3 in Table 1, all self- leadership scales were significantly positively correlated with global nAch $(r s=0.16-.39$, $p s<$ $0.05)$ although correlations were generally lower than in Study 1 but comparable to those from Study 2. Global self-leadership correlated significantly positively with hope for success $(r=0.41, p$ $<0.001)$, but not with fear of failure $(r=0.06, p>$ 0.10 ) as in Study 2. Differential associations for each of the three strategy domains were also found: Behavior-focused strategies were positively related to both hope for success and fear of failure (as in Study 2), natural reward strategies positively to hope for success (but not negatively to fear of failure as in Study 2), and constructive thought patterns only to hope for success (as in Study 2). Self-punishment correlated positively with fear of failure (as in Study 2) as did, interestingly, self-reward. Self-talk was only marginally 

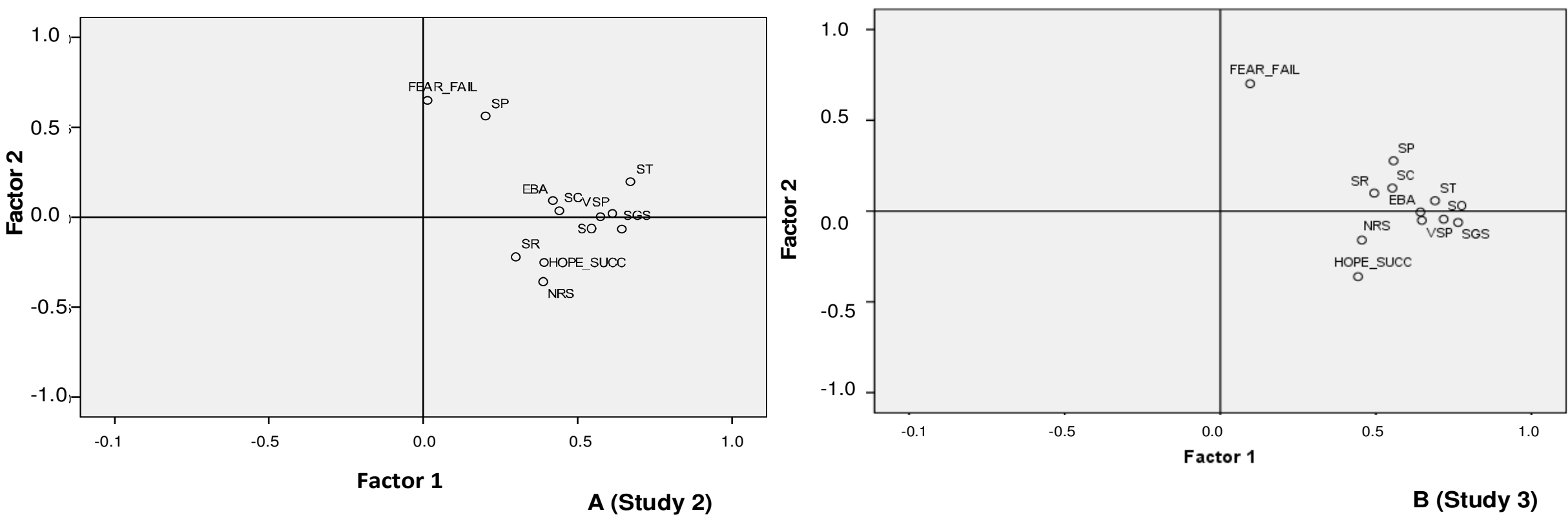

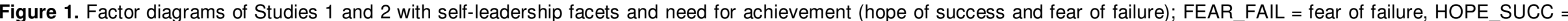

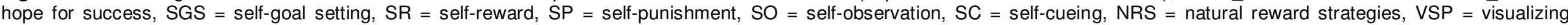
successful performance, ST = self-talk, EBA = evaluating beliefs and assumptions .

significantly correlated with fear of failure ( $r=$ $0.10,0.05<p<0.10)$. Overall, findings from Study 2 were replicated although there were some some differences in magnitude and direction of correlations (for example, natural reward strategies).

Additionally, we conducted a joint exploratory factor analysis (principal axis factoring, promaxrotation with $\mathrm{K}=4$ ) of self-leadership facet scales and nAch (hope for success and fear of failure), which yielded a two-factor solution (supported by Velicer's MAP test, Horn's parallel analysis, and scree-plot inspection) accounting for $40.37 \%$ of total variance (factor 1: $33.4 \%$, factor 2: $6.9 \%$ ). Factor 1 consisted of all self-leadership facets and hope of success, and factor 2 only of fear of failure (onto which hope of success showed a substantial secondary loading). The factor diagram can be seen in Figure 1B.

\section{DISCUSSION}

We conducted three studies to examine associations among self-leadership with subfacets and nAch. In all three studies, self-leadership scales were positively related to nAch (confirming our $\mathrm{H}_{1}$ ), but this was mainly driven by hope for success as Studies 2 and 3 point out (confirming our $\mathrm{H}_{2}$ ). The self-leadership subfacet self-punishment was positively correlated with fear of failure in Studies 1 and 2, which mostly drove the positive correlation between the self-leadership domain behavior-focused strategies and fear of failure.

The self-leadership domains natural reward strategies and constructive thought patterns were strongly related to hope for success, but not to fear of failure. Self-talk also showed tendencies towards correlations with fear of failure. Self-goal setting, self-observation, and natural reward strategies showed strongest correlations with nAch. There were also some differences in correlations between samples that could be attributed to different life contexts (students vs. workers). 


\section{Interpretation}

\section{Hope for success drives most self-leadership - nAch correlations}

In all three studies, the self-leadership subfacets self-goal setting and self-observation were most strongly related to nAch (specifically hope for success). For people with selfleading skills and people with achievement motivation, setting their own goals is important to achieve their selfset standards and maybe also excel these. Based on self-set standards, people seek out challenging goals (Locke and Latham, 1990). Constant self-observation may not only influence the successful maintenance of goal pursuit processes in self-leadership (Bandura, 1991), but also in nAch. People can thus monitor their progress in goal pursuit and compare it to their own "standards of excellence" for which heigh-tened levels of self-observation are required (Schunk, 2001). However, self-goal setting and self-observation may not arise from or be maintained by fear of failure, but rather hope for success as Studies 2 and 3 indicate. This dovetails nicely that the two self-leadership strategy domains natural reward strategies (finding joy and fun in one's tasks) and constructive thought patterns (charac-terized by positive and optimistic opportunity thinking) were uniquely associated with hope for success but not fear of failure. Natural reward strategies shift the attentional focus to inherently pleasant aspects of one's tasks which foster feelings of self-determination and com-petence (Deci and Ryan, 1985; Neck and Houghton, 2006). Constructive thought patterns shift negative thoughts to positive, constructive ones so that a positive future is realized in one's mental imagery (Neck and Houghton, 2006), which has been found to foster high performance (Driskell et al., 1994). Together with the fact that behavior-focused strategies are often used to influence oneself towards desirable, socially accepted, and positive behaviors, these findings are consistent with the positive, adaptive, and functional perspectives on self-leadership (Neck and Houghton, 2006). Further, they are supported by Lang and Fries (2006) who found that hope for success was particularly associated with a positive self-evaluation, self-goal setting, and intrinsic motivation, and fear of failure with negative self-evaluations.

Although Studies 1 and 2 used student samples (from the same university), correlations between self-leadership and nAch were particularly high in Study 1 . These were likely inflated because the nAch measure did not contain any information on avoidance tendencies or fear of failure, but only items capturing hope for success content. Thus, essentially a hope for success nAch was measured in Study 1 which can explain the particularly large correlations. Also, it should be noted that the self-leadership and nAch scales contain a lot of item content that refers to overt or phenotypic expressions of the constructs, and due to the goal and performance character that ties together both constructs higher correlations may have resulted. Thus theoretically and empirically, self-leadership and nAch are different (but phenotypically similar) constructs.

\section{Self-leadership - nAch associations are context- specific}

Our findings further indicate that, despite largely consistent findings over three studies, life contexts and normative roles may play a role in self-leadership - nAch associations. Self-reward was correlated with global nAch, hope for success, and even fear of failure in the professional's sample, but not in the student sample. While self-punishment was unrelated to the hope for success and related to fear of failure in the student sample, it was related to both factors in the professional's sample. Natural reward strategies showed a negative correlation with fear of failure in the student sample, but none in the professional's sample. Further, self-talk was only in the student sample clearly associated with fear of failure. This might be indicative of different context-specific demands in students' versus professionals' lives as (a) quality and quantity of goals, (b) the extent to which goals can be chosen, and (c) pursuit processes of these goals (for example, duration, regulation strategies used, etc.) differ (besides age, social roles, and socio-economic status). One can expect students who usually start learning and exhibiting maximum performance at the end of the semester for exams in subjects they may not really be interested in to be less intrinsically motivated and have more fear of failure because of the grade system and immediate feedback provided through exams. This may also account for more self-punishment (for example, withdrawing from social contacts and fun to learn for an exam) and negative forms of self-talk (Neck and Houghton, 2006). In contrast, professionals constantly have to perform and thus keep themselves motivated to do so. This can explain the positive intercorrelations between self-reward and self-punishment with hope for success and fear of failure. It seems that workers may need to make use of different strategies to keep their focus, stay motivated, and perform well. We want to point out that the overall pattern of results was consistent and robust in all three studies so that our findings may be generalized, but nonetheless do we stress that specific life contexts should be taken into account here as correlational patterns may change to some extent.

\section{LIMITATIONS AND PROSPECTS}

To the best of our knowledge, we were the first to empirically disentangle self-leadership and nAch with respective subfacets and in different samples (students vs. workers) to demonstrate that self-leadership shows differential associations with hope for success versus fear of failure. However, there remain some limitations.

First, we did not sample actual performance and relied 
on self-reports of self-leadership skills and nAch. Thus, we cannot draw any conclusions on real-life outcomes. Also, we did not sample any information on goals (such as, which nature they were, how they were pursued, etc.), but relied on different samples to account for different sets of goals (university- vs. work-related ones).

Second, we cannot provide causal inferences as to whether underlying nAch breeds self-leadership strategies or self-leadership strategies breed heightened nAch. It is likely that there is a combination of both, but such questions need to be addressed by cross-lagged autoregressive models in longitudinal studies.

Third, we only used explicit measures of nAch and thus sampled people's achievement-related cognitive representations of preferences. Future studies could complement this with implicit nAch measures (via TATs, IATs, or achievement-cue related response times).

Fourth, despite extensive theorizing on self-leadership (Neck and Houghton, 2006), it has barely been thoroughly empirically investigated and sufficiently operationalized (especially regarding discriminant aspects to other constructs such as self-control, self-influence, selfregulation, and self-management) to have produced psychometrically sound measures. We have employed a German version of the most widely used revised selfleadership questionnaire (Houghton and Neck, 2002), but propose that validity and reliability of self-leadership scales should be enhanced (as can be seen in the low reliability we found in the natural reward strategies scale; Furtner and Rauthmann, 2010). Self-leadership remains as of now, a fuzzy and blurry construct, comprising several and not necessarily interrelated constructs. It should be clarified (a) which components of self-leadership - as a macro-construct - are dispositional (that is, due to individual differences in personality variables) or strategic (that is, acquired as a specific adaptation to environmenttal circumstances to produce enhanced performance), (b) which strategies self-leader-ship exactly comprises, (c) which underlying (personality) structures, processes, and dynamics drive phenotypical self-leadership strategies, and (d) as to which extent self-leadership strategies can be learned and enhanced. Such questions need to be addressed to show that self-leadership is a distinct construct worthy of its own stands of systematic research. Our study provided evidence that self-leadership is linked to nAch, but is not subsumed by it.

Ideally, associations among self-leadership scales and nAch should be longitudinally examined with superior scales, explicit and implicit motive measures, real-life criteria (for example, performance), and different aspects of pursued goals (contents and processes) in future indepth research for which we have provided first steps in this work.

\section{Conclusion}

Self-leadership and nAch share similarities such as a goal-focused operationalization, embedding in motivational literature, and heightened levels of performance. However, they should nonetheless be considered two separate constructs on distinct conceptual levels. Ontogenetically speaking, motives underlie self-regulatory strategies because these strategies are acquired by adaptation to environmental demands which are strongly linked to people's needs and goals (as they can foster or hinder them). This implies that motives such as nAch may underlie or drive phenotypical self-leadership strategies (that is, self-leadership stands in service of one's nAch), but self-leadership and nAch are different concepts and none of them is a subcomponent of the other (being, conceptually and empirically, on different levels). Conceptually, self-leadership refers to a process, that is, how something should be done (Neck and Houghton, 2006). If and why something is done and what is done is a matter of motives and goals, though. In three studies and across different samples, we clarified relationships among self-leadership and nAch, providing evidence that they are especially linked to each other via hope for success which reflects the positivistic outlook of selfleadership.

\section{REFERENCES}

Andressen P, Konradt U (2007). Messung von Selbstführung: Psychometrische Überprüfung der deutschsprachigen Version des Revised Self-leadership Questionnaire. [Measurement of Selfleadership: a psychometric analysis of the German version of the Revised Self-leadership Questionnaire]. Z Pers. Psychol., 6(3): 117128.

Bandura A (1991). Social cognitive theory and self-regulation. Organ Behav. Hum. Decis. Process., 50(2): 248-287.

Atkinson JW (1957). Motivational determinants of risk-taking behavior. Psychol. Rev., 64(1/6): 359-372.

Carver CS, Scheier MF (1998). On the self-regulation of behavior. Cambridge: Cambridge University Press.

Deci E, Ryan R (1985). The support of autonomy and control of behavior. J. Pers. Soc. Psychol., 53(6): 1024-1037.

Driskell JE, Copper C, Moran A (1994). Does mental practice enhance performance?. J. Appl. Psychol., 79(4): 481-492.

Elliot AJ (2006). The hierarchical model of approach-avoidance motivation. Motiv. Emot., 30(2): 111-116.

Elliot AJ, Church MA (1997). A hierarchical model of approach and achievement motivation. J. Pers. Soc. Psychol., 72(1): 218-232.

Elliot AJ, Fryer JW (2008). The goal concept in psychology. In J. Shah \& W. Gardner (Eds.), Handbook of motivational science. New York: Guilford Press, pp. 235-250.

Furtner MR, Rauthmann JF (2010). Relations between self-leadership and scores on the Big Five. Psychol. Rep., 107(2): 339-353.

Furtner MR, Rauthmann JF, Sachse P (2011). The self-loving selfleader: An examination of the relationship between self-leadership and the Dark Triad. Soc. Behav. Pers., 39(3): 369-380.

Guzzo RA (1998). Leadership, self-management, and levels of analysis. In F. Danserau \& F. J. Yammarino (Eds.), Leadership: the multiplelevel approaches, classical and new wave. Stanford, CT: JAI Press. pp. 213-219

Houghton JD, Neck CP (2002). The revised self-leadership questionnaire: Testing a hierarchical factor structure for Selfleadership. J. Manage. Psychol., 17(8): 672-691.

Lang JWB, Fries S (2006). A revised 10-item version of theAchievement Motives Scale: Psychometric properties in German-speaking samples. Eur. J. Psychol. Assess., 22(3): 216-224.

Locke EA, Latham GP (1990). A theory of goal setting and task 
performance. Englewood Cliffs, NJ: Prentice-Hall.

Manz CC (1986). Self-leadership: Toward an expanded theory of selfinfluence processes in organizations. Acad. Manage. Rev., 11(3): 585-600.

Manz CC, Sims HP Jr. (1980). Self-management as a substitute for leadership: A social learning perspective. Acad. Manage. Rev., 5(3): 361-367.

Markham SE, Markham IS (1995). Self-management and selfleadership reexamined: A levels of analysis perspective. Leadersh. Q., 6(3): 343-359.

McClelland DC (1965). Toward a theory of motive acquisition. Am. Psychol., 20(5): 321-333.

McClelland DC, Koestner R, Weinberger J (1989). How do selfattributed and implicit motives differ? Psychol. Rev., 96(4): 690-702.

Murray HA (1938). Explorations in personality. New York: Oxford University Press.

Neck CP, Houghton JD (2006). Two decades of self-leadership theory and research: Past developments, present trends, and future possibilities. J. Manage. Psychol., 21(4): 270-295.
Neck CP, Manz CC (1992). Thought self-leadership: The influence of self-talk and mental imagery on performance. J. Organ. Behav., 13(7): 681-699.

Robbins SB, Lauver K, Le H, Davis D, Langley R, Carlstrom A (2004). Do psychosocial and study skill factors predict college outcomes? A meta-analysis. Psychol. Bull., 130(2): 261-288.

Schuler H, Prochaska M (2001) Leistungsmotivationsinventar [Achievement Motivation Inventory]. Goettingen: Hogrefe.

Schunk DH (2001). Social cognitive theory and self-regulated learning. In Zimmerman BJ, Schunk DH, Self-regulated learning and academic achievement Mahwah, NJ: Lawrence Erlbaum, pp. 125-152.

Spangler WD (1992). Validity of questionnaire and TAT measures of need for achievement: Two meta-analyses. Psychol. Bull., 112(1): 140-154. 